\title{
PENGARUH STIMULAN AKAR DAN MEDIA TANAM PADA PERTUMBUHAN SETEK PUCUK PANGAL (Baccaurea bracteata Muell.Arg.)
}

(The Effect of Root Stimulant and Planting Medium on Growth of Baccaurea bracteta Muell.Arg Shoot Cuttings)

\section{F. Mentari ES, Reine Suci Wulandari}

Fakultas Kehutanan Universitas Tanjungpura Pontianak. Jl. Daya Nasional Pontianak 78124

Email: fransiska_tari@yahoo.com

Abstract

Pangal (Baccaurea bracteata Muell.Arg.) is a flowering plant belonging to the Phylanhace tribe know as fruit and wood producer. The pangal plant is native to debt, but its existence is diminishing now. Therefore, it is necessary to procure seedlings for forest restoration with cuttings. The purpose of this study was to obtain root stimulants and planting medium suitable for the growth of pangan shoot cuttings. This experiment used a (split plot) design with a completely randomized design (CRD). The main plot factor was the planting medium with two levels of factor (cocopeat $\left(M_{1}\right)$ and cocopeat with husk charcoal $\left.\left(M_{2}\right)\right)$. The subplot factor consists of three levels of factor (control $\left(Z_{1}\right)$, rootone- $F\left(Z_{2}\right)$ and wood vinegar $\left(Z_{3}\right)$ ). Each treatment was replicated five times to obtain 30 units of treatments. The result showed the highest percentage of life (60\%) was obtained by in cuttings that were treated with rootone-F and were planted in cocopeat medium and rice huck mixture. After being tested statistically, the effect of planting media (cocopeat or mixture of cocopeat and husk charcoal) and root stimulants (without root stimulants, rootone $F$ or wood vinegar) was not significant to primary root length, primary root number, secondary root number, number of leaves and shoot length.

Keyword: Baccaurea bracteata, husk charcoal wood vinegar, rootone-F.

\section{PENDAHULUAN}

Luasan hutan gambut di Indonesia mencapai 14,9 juta ha dilihat dari luasan daratan Indonesia, akan tetapi semakin tahun semakin berkurang karena mengalami kerusakan (Pahlipi et al. 2017). Kerusakan yang terjadi di hutan gambut karena kebakaran, yang mengakibatkan berkurangnya luasan hutan dan berkurangnya jumlah tanaman asli hutan gambut sehingga perlu usaha untuk memperbaiki hutan gambut salah satunya melalui restorasi hutan gambut. Upaya restorasi hutan gambut yang terdegradasi dapat dilakukan dengan menanam jenisjenis tumbuhan lokal hutan gambut, salah satunya tanaman pangal (Baccaurea bracteata Muell.Arg.). Pangal adalah salah satu tanaman yang dapat diperbanyak dengan cara generatif dan vegetatif. Perbanyakan secara generatif dapat melalui biji pangal, namun biji pangal sulit diperoleh karena keberadaannya di hutan gambut semakin berkurang. Mendapatkan biji pangal memerlukan waktu yang cukup lama sehingga digunakan alternatif secara vegetatif dengan setek pucuk. Perbanyakan tanaman melalui setek pucuk telah berhasil dengan baik untuk jenis $H$. odora dan $H$. sangal dengan persentase berakar 90\% (Sakai et al. 2007).

Perbanyakan vegetatif dengan setek pucuk merupakan salah satu upaya untuk mendapatkan bibit unggul. Bibit unggul 
adalah yang memiliki kualitas baik terhindar dari penyakit dan dalam waktu yang singkat bibit yang dibutuhkan akan terpenuhi, serta bibit yang dihasilkan akan lebih banyak, kualitas bibit yang baik dapat dilihat dari pertumbuhan panjang akar, panjang tunas, dan jumlah daun (Prakasa 2011). Pertumbuhan akar dapat distimulasi oleh media dan stimulan akar yang sesuai. Media tanam yang umumnya digunakan adalah (cocopeat dan arang sekam) yang memiliki kelebihan mampu mengikat air sehingga kelembapan setek pucuk tetap terjaga, dibandingkan dengan media lain seperti pasir (Danu et al. 2012). Stimulan akar sintetis yang umum digunakan adalah IBA, NAA, IAA atau dalam kemasan komersil rootone-F. Alternatif lain stimulan akar yang dapat digunakan adalah stimulan organic seperti cuka kayu untuk merangsang pertumbuhan akar. Cuka kayu merupakan senyawa organik yang dapat dihasilkan dari gas dan pembakaran kayu segar. Kandungan utama cuka kayu seperti asam asetat, formaldehida, etil-valerat dan methanol yang dapat diaplikasikan dalam proses industri dan pertanian yang mampu meningkatkan kualitas, pengusir hama dan mempercepat pertumbuhan tanaman (Apai et al. 2001).

Tujuan penelitian ini untuk mendapatkan stimulan akar dan media tanam yang sesuai untuk pertumbuhan setek pucuk pangal. Manfaat penelitian ini untuk pengembangan ilmu pengetahuan Silvikultur, khususnya dalam pengadaan bibit unggul melalui perbanyakan setek pucuk tanaman pangal dengan menggunakan media (cocopeat dan arang sekam) dan stimulan akar (cuka kayu dan rootone-F).

\section{METODE PENELITIAN}

Penelitian dilakukan di Laboratorium Silvikultur Kehutanan Untan dan rumah kasa bursa anggrek Pontianak (Lembaga penelitian) dengan waktu selama kurang lebih 3 bulan. Bahan yang digunakan adalah setek pucuk pangal yang diambil di Hutan Sekunder Kuala Dua, media tanam cocopeat + arang sekam, stimulan akar (rootone-F dan cuka kayu), aquades sebagai pelarut, betadine sebagai antiseptik, kapas digunakan untuk menjaga kelembapan bahan setek pada saat diambil dari lapangan. Alat yang digunakan antara lain paranet untuk menaunggi setek pucuk, pot tray untuk penempatan media tanam, box propagasi sebagai tempat untuk menyimpan pot tray, gunting setek untuk pemotogan bahan setek, alumunium foil sebagai membungkus kapas pada saat pengambilan bahan setek di lapangan, ice box untuk menyimpan bahan setek pada saat di lapangan, termohigrometer untuk mengukur suhu udara dan kelembapan udara, gelas ukur digunakan untuk mengukur larutan cuka kayu.

\section{Pelaksanaan Penelitian}

\section{Persiapan media tanam}

Media tanam yang digunakan adalah cocopeat dan arang sekam. Media tanam cocopeat dicuci dengan menggunakan air mineral sampai bersih. Media tanam campuran cocopeat dan arang sekam dibuat dengan perbandingan 2:1.

\section{Pengambilan bahan setek}

Bahan setek pangal diambil dari semai pangal yang tumbuh di hutan sekunder 
Kuala Dua. Pucuk pangal dipotong sepanjang 20-30 cm dan dibungkus dengan kapas basah kemudian dilapisi dengan aluminium foil pada bagian pangkal kemudian disimpan dalam ice box.

Persiapan setek pucuk

Setek pucuk pangal dipotong di dalam air sampai pada pangkal daun kedua atau ketiga sepanjang $3 \mathrm{~cm}$. Masing-masing setek pucuk sebelum diberi perlakuan direndam dengan antiseptik sebanyak 20 tetes dalam $250 \mathrm{~mL}$ air selama 10 menit.

Pembuatan dan pemberian stimulan akar

Pasta rootone-F dibuat dengan cara, rootone-F sebanyak $36 \mathrm{~g}$ diberi air sampai membentuk pasta kemudian diolesi ke bahan setek pucuk yang telah dipotong. Larutan cuka kayu konsentrasi 4\% dibuat dengan cara $10 \mathrm{~mL}$ cuka kayu di larutkan kedalam $250 \mathrm{~mL}$ air. Setek pucuk yang telah di potong direndam ke dalam larutan cuka kayu 4\% selama 10 menit.

Penanaman setek pucuk

Setelah setek pucuk diberi masingmasing perlakuan, setek pucuk ditanam pada media tanam cocopeat dan arang sekam yang telah diisi kedalam pot tray sesuai dengan kode unit percobaan.

Pemeliharaan

Pemeliharaan setek pucuk pangal dilakukan dengan cara menjaga kelembapan boxks propagasi dengan penyemprotan air yang dilakukan tiga kali sehari yaitu pagi, siang dan sore. Penyemprotan dilakukan pagi dari jam 06:00-07:00, siang jam 12:00-13:00, sore jam 17:00-18:00.

\section{Rancangan Percobaan dan Analisis} Data
Penelitian ini menggunakan metode eksperimen dengan rancangan petak terbagi (spit plot) dengan pola dasar rancangan acak lengkap (RAL). Faktor petak utamanya adalah media tanam dengan dua taraf (cocopeat $\left(\mathrm{M}_{1}\right)$ dan cocopeat dengan arang sekam $\left(\mathrm{M}_{2}\right)$, dan faktor anak petak adalah stimulan akar yang terdiri dari tiga taraf yaitu kontrol $\left(Z_{1}\right)$, rootone-F $\left(Z_{2}\right)$, cuka kayu $\left(Z_{3}\right)$. Masing-masing perlakuan diulang sebanyak lima kali sehingga diperoleh 30 satuan percobaan.

Variabel penelitian yang diukur di akhir penelitian (3 bulan minggu setelah tanam) adalah persentase (\%) hidup setek, panjang akar primer $(\mathrm{cm})$, jumlah akar primer (helai), jumlah akar sekunder (helai). Variabel pertambahan jumlah daun, dilakukan dengan menghitung jumlah daun (helai) yang tumbuh dan variabel pertambahan panjang tunas $(\mathrm{cm})$ yang diukur setiap 2 minggu sekali selama 12 minggu.

Uji kehomogenan ragam Bartlett dilakukan sebelum analisis ragam, dengan rumus:

$S_{i^{2}}=\frac{n \sum_{X_{i^{2}}}-\left(\sum X_{i}\right)^{2}}{n(n-1)}$

Di mana :

$$
\begin{aligned}
\mathrm{S}_{\mathrm{i}}{ }^{2} & =\text { Varians gabungan } \\
\mathrm{n} & =\text { Banyaknya data } \\
\mathrm{x} & =\text { Banyaknya kelompok data }
\end{aligned}
$$

Apabila analisis ragam menunjukan perlakuan berpengaruh nyata atau sangat nyata, maka selanjutnya dilakukan uji beda nyata jujur (BNJ) pada tingkat kepercayaan $5 \%$ dan $1 \%$ untuk menentukan perbedaan antar perlakuan. 


\section{HASIL DAN PEMBAHASAN}

Tabel 1 menunjukkan bahwa pemberian rootone-F dan cuka kayu 4\% pada setek pucuk pangal belum signifikan dapat meningkatkan pertumbuhan akar dan pertumbuhan tunas (daun dan panjang tunas) pangal selama 12 minggu setelah tanam (MST). Salah satu faktor yang mempengaruhi pertumbuhan tanaman adalah hormon. Tanaman pada dasarnya sudah memiliki hormon endogen, tetapi hormon yang dimiliki dalam jumlah yang sedikit sehingga hormon tersebut tidak cukup untuk proses pertumbuhan setek pucuk (sriyanti 2000). Oleh karena itu untuk memacu pertumbuhan setek pucuk perlu menambahkan stimulan akar seperti rootone-F dan cuka kayu. Konsentrasi stimulan akar yang paling tepat untuk jenis berbeda tergantung pada kandungan hormon masing-masing tanaman. Konsentrasi stimulan akar yang diberikan terlalu rendah akan mengakibatkan respon pertumbuhan tanaman akan lama, sedangkan konsentrasi dalam jumlah yang tinggi akan mengakibatkan pertumbuhan tanaman akan terhambat.

Tabel 1. Rekapitulasi hasil sidik ragam pengaruh stimulan akar dan media tanam pada pertumbuhan setek pucuk pangal selama 12 minggu setelah tanam (MST) (Recapitulation of the analyses of variance results of the effect of root stimulant and planting media on growth of pangal shoots cuttings for 12 weeks after planting (WAT)

\begin{tabular}{|c|c|c|c|c|c|}
\hline $\begin{array}{c}\text { Sumber } \\
\text { keragaman }\end{array}$ & $\begin{array}{c}\text { Panjang } \\
\text { akar } \\
\text { primer }(\mathbf{c m}) \\
\end{array}$ & $\begin{array}{c}\text { Jumlah akar } \\
\text { primer } \\
\text { (helai) }\end{array}$ & $\begin{array}{c}\text { Jumlah akar } \\
\text { sekunder } \\
\text { (helai) } \\
\end{array}$ & $\begin{array}{c}\text { Jumlah } \\
\text { daun } \\
\text { (helai) }\end{array}$ & $\begin{array}{c}\text { Panjang } \\
\text { tunas } \\
\text { (cm) }\end{array}$ \\
\hline media tanam & $0,03^{\text {tn }}$ & $0,2^{\text {tn }}$ & $0,02^{\text {tn }}$ & $3,25^{\text {tn }}$ & $0,67^{\text {th }}$ \\
\hline $\begin{array}{l}\text { stimulan akar } \\
\text { interaksi } \\
\text { (media x }\end{array}$ & $0,53^{\text {tn }}$ & $1,01^{\mathrm{tn}}$ & $0,50^{\text {tn }}$ & $1,78^{\mathrm{tn}}$ & $1,32^{\operatorname{tn}}$ \\
\hline stimulan akar & $0,13^{\text {th }}$ & $0,15^{\text {tn }}$ & $0,13^{\text {tn }}$ & $0,51^{\mathrm{tn}}$ & $0,48^{\text {tn }}$ \\
\hline
\end{tabular}

Keterangan $\mathrm{tn}=$ tidak nyata

Tabel 2 menunjukkan bahwa persentase hidup tanaman pangal cenderung mampu meningkatkan persentase hidup setek pada perlakuan menggunakan rootone-F yang ditanam di media cocopeat atau campurannya dengan arang sekam, yaitu diatas $50 \%$.
Persentase hidup setek pucuk yang menggunakan media tanam cocopeat yang tidak diberi stimulan akar dan perlakuan menggunakan media tanam cocopeat dengan arang sekam yang diberi cuka kayu 4\% hanya di bawah $50 \%$. 
Tabel 2. Persentase (\%) hidup setek pucuk pangal selama 12 minggu setelah tanam (MST) (Percentage (\%) of live of pangal shoot cuttings for 12 weeks after planting (WAT)

\begin{tabular}{cccc}
\hline \multirow{2}{*}{ Media } & \multicolumn{3}{c}{ Stimulan akar } \\
\cline { 2 - 4 } & Tanpa & Rootone-F & Cuka kayu \\
\hline Cocopeat & 20 & 60 & 40 \\
Cocopeat dengan arang sekam & 40 & 60 & 20
\end{tabular}

Payung et al. (2014) memaparkan bahwa rootone-F sebanyak 1.500 ppm mampu memberikan hasil persentase hidup terhadap setek tembesu sebesar $90 \%$ dibandingkan dengan perlakuan tanpa diberi rootone-F memberikan hasil persentase hidup 50\%. Selain perlakuan yang diberi rootone-F, perlakuan yang diberi cuka kayu sebanyak 4\% juga mampu merangsang pertumbuhan akar, daun dan tunas pada tanaman pangal meskipun dalam jumlah yang sedikit.

\section{Pertumbuhan Akar Setek Pucuk Pangal}

Tabel 3 menunjukkan perlakuan dengan media tanam cocopeat dan campuran arang sekam yang diberi rootone-F cenderung mampu meningkatkan pertumbuhan panjang akar primer, jumlah akar primer dan jumlah akar sekunder dibandingkan dengan perlakuan lainnya. Putra et al. (2014) memaparkan bahwa jabon putih yang diberi stimulan akar rootone-F sebanyak 200 ppm menghasilkan persentase tumbuh sebesar $96 \%$ dengan panjang akar 19,60 $\mathrm{cm}$ dan panjang tunas $20,47 \mathrm{~cm}$. Hal ini disebabkan pada rootone-F adanya auksin seperti IBA, IAA dan NAA yang berperan sebagai pembentukan jumlah daun dan panjang akar pada tanaman (Budianto et al. 2013).

Tabel 3. Rerata pertumbuhan akar setek pucuk pangal selama 12 minggu setelah tanam (MST) (The average of roots growth of pangal cuttings for 12 weeks after planting (WAT)

\begin{tabular}{cccc}
\hline \multirow{2}{*}{ Media } & \multicolumn{3}{c}{ Stimulan akar } \\
\cline { 2 - 4 } & Tanpa & Rootone-F & Cuka kayu \\
\hline & ------- & Panjang akar primer (cm) & --------- \\
Cocopeat & 29,5 & 31,8 & 14,9 \\
Cocopeat dengan arang sekam & 16,7 & 42 & 13,7 \\
\hline \multirow{2}{*}{ Cocopeat } & ------- & Jumlah akar primer (helai) & -------------- \\
Cocopeat dengan arang sekam & 8 & 9 & 3 \\
\hline \multirow{2}{*}{ Cocopeat } & 5 & 12 & 2 \\
\hline \multirow{2}{*}{ Cocopeat dengan arang sekam } & ------- & Jumlah akar sekunder (helai) & --------------- \\
& 97 & 88 & 42 \\
\hline
\end{tabular}


Tabel 4. Rerata pertumbuhan tunas setek pucuk pangal selama 12 minggu setelah tanam (MST) (The average of bud growth of pangal shoot cuttings for 12 weeks after planting (WAP)

\begin{tabular}{lccc}
\hline \multirow{2}{*}{ Media } & \multicolumn{3}{c}{ Stimulan akar } \\
\cline { 2 - 4 } Cocopeat & Tanpa & Rootone-F & Cuka kayu \\
\hline & 11 & Jumlah daun (helai) & ------------- \\
Cocopeat & 16 & 25 & 17 \\
Cocopeat dengan arang sekam & 3,1 & 25 & 7 \\
\hline Cocopeat dengan arang sekam & 2,5 & 5,5 & 4,3 \\
\hline Tabel 4 menunjukkan bahwa pada & et al. (1997) memaparkan bahwa auksin \\
variabel jumlah daun dan panjang tunas & berperan sebagai pembentukan akar, \\
cenderung meningkat pertumbuhannya & pembentukan daun pada tanaman, \\
pada perlakuan dengan menggunakan & sedangkan yang diberi stimulan akar \\
media tanam berbeda yang diberi & cuka kayu cenderung meningkat \\
rootone-F. Hasil penelitian yang telah & meskipun tidak setinggi yang diberi \\
dilakukan untuk semua variabel & rootone-F. Haji (2010) memaparkan \\
cenderung meningkat pada saat & bahwa pemberian cuka kayu mampu \\
perlakuan menggunakan media tanam & meningkatkan pertambahan jumlah \\
berbeda yang diberi stimulan akar & daun dan pertumbuhan tunas pada \\
rootone-F. Hal ini disebabkan pada & tanaman Gymura pseudochna Lour DC.
\end{tabular}
rootone-F terkandung auksin. Hartman

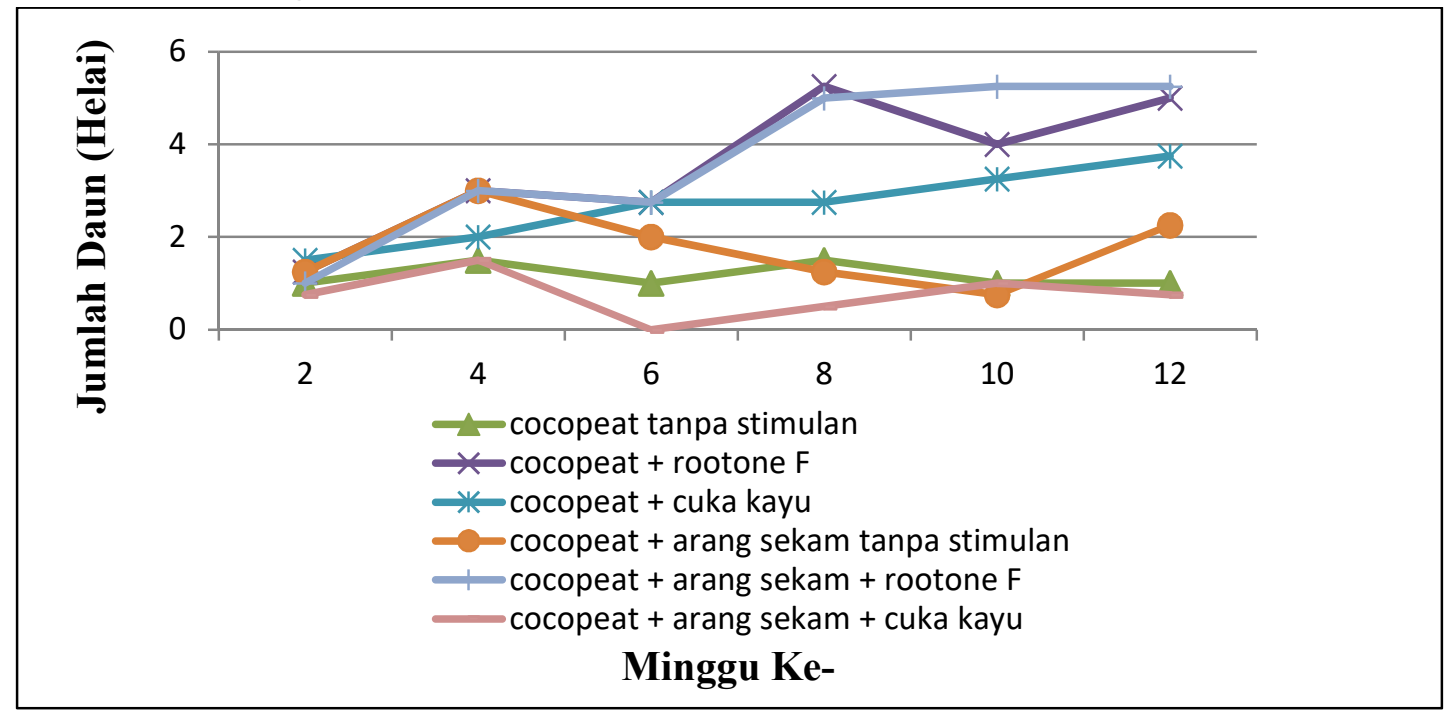

Gambar 1. Grafik pertambahan jumlah daun setek pucuk pangal (The grafh of increasing number of leaves pangal shoot cuttings)

Gambar 1 memperlihatkan rootone-F $36 \mathrm{~g}$, sedangkan perlakuan pertambahan jumlah daun meningkat pada menggunakan media tanam cocopeat perlakuan menggunakan media tanam dengan arang sekam yang diberi cuka cocopeat dengan arang sekam yang diberi kayu $4 \%$ cenderung menurun. 


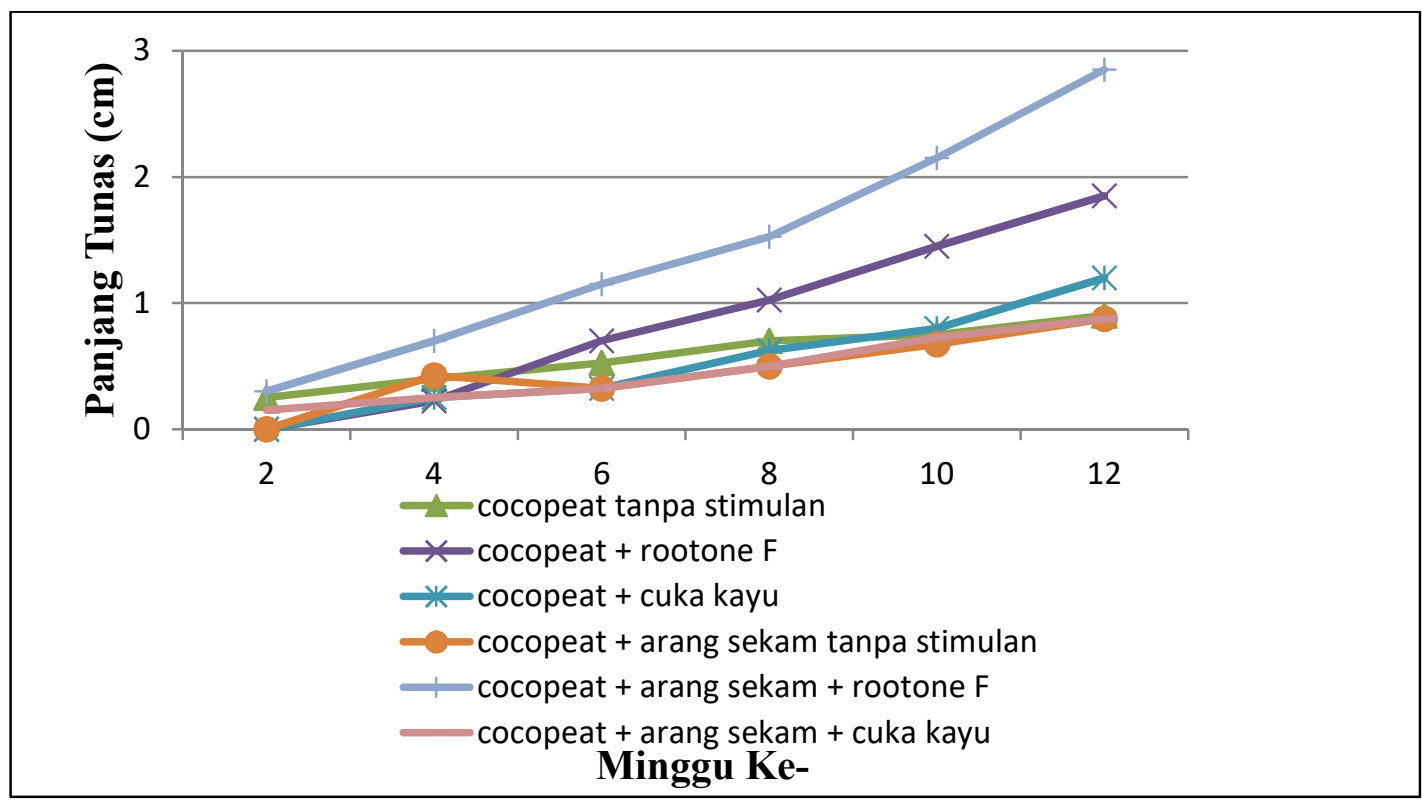

Gambar 2. Grafik pertambahan panjang tunas setek pucuk pangal (The increasing of bud length of pangal shoot)

Gambar 2 menunjukkan tren pemanjangan tunas setek pangal yang diberi stimulan akar rootone $\mathrm{F}$, baik yang ditanam dimedia cocopeat maupun arang sekam, yang lebih progresif apabila dibandingkan dengan stimulan cuka kayu dan tanpa stimulan akar.

Berdasarkan hasil akhir pertumbuhan pucuk baik jumlah daun maupun panjang tunas, perlakuan dengan menggunakan media tanam berbeda yang diberi rootone-F cenderung meningkat dibandingkan perlakuan lainnya. Rootone-F yang diberikan pada setek pucuk dapat memacu kerja giberelin dalam pemanjangan ruas-ruas sehingga dapat meningkatkan jumlah nodus (tempat duduk daun dan tumbuh daun). Hal ini karena yang terkandung dalam rootoneF tersebut terdapat auksin yang selanjutnya akan berpengaruh terhadap penambahan jumlah daun pada tanaman
(Salisbury et al. 1995). Selain rootoneF, cuka kayu juga dapat memacu penambahan jumlah daun dan panjang tunas walaupun tidak setinggi yang diberi rootone-F. Komarayati et al. (2013) memaparkan bahwa tanaman sengon dan jabon meningkat pertumbuhan tinggi dan diameternya dengan diberi perlakuan dengan menggunakan media tanam arang sekam yang diberi cuka kayu.

\section{Potensi Cuka Kayu dan Rootone-F untuk Mendukung Pertumbuhan Setek Pucuk Pangal}

Penggunaan stimulan akar cuka kayu 4\% dan rootone-F pada media tanam cocopeat dan arang sekam pada semua variabel belum signifikan pengaruhnya pada pertumbuhan setek pucuk pangal selama 12 minggu pengamatan. Namun, tidak berarti bahwa cuka kayu tidak lebih baik dari rootone F, karena perbedaan hasil diantara kedua perlakuan tersebut tidak 
signifikan. Hal ini menunjukkan bahwa cuka kayu masih berpotensi untuk dikembangkan. Pada penelitian ini, konsentrasi cuka kayu 4\% belum dapat meningkatkan pertumbuhan setek pucuk pangal. Oleh karena itu, perlu juga mempertimbangkan untuk meningkatkan konsentrasi cuka kayu lebih dari $4 \%$ atau dengan menambah waktu (lama) perendaman setek dalam larutan cuka kayu. Konsentrasi stimulan akar yang tepat sangat penting untuk menunjang pertumbuhan setek pangal. Apabila konsentrasinya terlalu tinggi dapat berdampak buruk pada setek. Hal ini disebabkan pemberian terlalu tinggi akan menghambat pertumbuhan. sebaliknya pemberian terlalu rendah akan mengakibatkan lambatnya pertumbuhan.

Rendahnya keberhasilan setek pucuk pangal dapat dipengaruhi oleh faktor lingkungan (Danu et al. 2011). Faktor lingkungan yang dapat mempengaruhi keberhasilan setek seperti suhu udara dan kelembapan udara. Suhu udara pada saat penelitian di lapangan sebesar $39,41^{\circ} \mathrm{C}$, sedangkan untuk kelembapan sebesar 81,41\%. Putri et al. (2018) memaparkan bahwa suhu yang terbaik untuk mendukung proses pertumbuhan setek pucuk berkisar antara $25-30^{\circ} \mathrm{C}$. Kelembapan yang mendukung proses pertumbuhan setek pucuk berkisar antara 80-90\% (Rahardiyanti 2005).

\section{KESIMPULAN}

Perlakuan dengan menggunakan media tanam (cocopeat dan arang sekam), yang diberi stimulan akar
(rootone-F dan cuka kayu) untuk pertumbuhan setek pucuk pangal belum dapat menstimulasi peningkatan pertumbuhan setek pucuk tanaman pangal (Baccaurea bracteata Muell.Arg).

\section{SARAN}

Penelitian lebih lanjut diperlukan dengan mempertimbangkan peningkatan konsentrasi stimulan akar dan lama perendaman setek dalam stimulan akar.

\section{UCAPAN TERIMA KASIH}

Terima kasih kepada SEAMEO BIOTROP melalui Dr. Ir. Hanna Artuti Ekamawanti (sebagai Ketua Peneliti) yang telah membantu dana penelitian ini dari penelitian DIPA Biotrop 2017 yang berjudul "Pengembangan Sistem Paludikultur untuk Lahan Gambut dan Teknik Propagasi Tumbuhan Indigenos".

\section{DAFTAR PUSTAKA}

Apai W, Thongdeethae S. 2001. Wood vinegar: new organic for thai agriculture. the 4th toxicity division conference. Bangkok: Departemen Of Agriculture.

Budianto MI, Ahmad AM, Suhartono. 2013. Pertumbuhan setek cabe jamu (Piper retrofractum.Vahl) pada berbagai campuran media tanam dan konsentrasi zat pengatur tumbuh rootone-F. Agrivigor 6:110-112.

Danu, Subiakto A, Putri KP. 2011. Uji setek pucuk damar (Agathis loranthifolia Salisb) pada berbagai media dan zat pengatur tumbuh. Jurnal Penelitian Hutan dan Konservasi Alam 8:245-252. 
Danu, Putri KP. 2012. Perbanyakan tanaman kilemo (Litsea cubeba L Person) dengan teknik setek pucuk. Tekno Hutan Tanaman 51:1-6.

Gaspersz V. 1994. Metode Perancangan Percobaan. Bandung: CV ARMICO.

Hartman HT, Kester DE, Daniel FT, Geneve RL. 1997. Plan Propagation Principles and Practices, Prentice Hall Cliffs. New Jersey: Englewood

Pahlipi, Ridha M. 2017. Emisi gas karbon dioksida (CO2) pada perkebunan kelapa sawit (Elaeis guineesisJacq) yang ditumpangsari dengan tanaman pangan di lahan gambut. Jurnal Agroteknologi 7:35-42.

Payung D, Susilawati. 2014. Pengaruh zat pengatur tumbuh rootone-F dan sumber bahan setek terhadap pertumbuhan setek tembesu (Fagraea fragrans) di PT Jorong Barutama Greston Kalimantan Selatan. Enviro Scienteae 10:133139.

Prakasa KE. 2011. Pengaruh Pemberian ZPT (Root-one F) Terhadap Pertumbuhan Setek Duabangsa moluccana, Blume [skripsi]. Bogor (ID): IPB.

Putra F, Indriyanto, Riniarti M. 2014. Keberhasilan hidup setek pucuk jabon (Anthocephalus cadamba) dengan pemberian beberapa konsentrasi rootone-F. Jurnal Sylva Lestari 2:33-40.

Putri BF, Fakhrurozi Y, Rahayu S. 2018. Pengaruh perbedaan jenis media tanam terhadap pertumbuhan setek (Hoya coronaria) berbunga kuning dari kawasan hutan kerangas air anyir, Bangka. Jurnal Penelitian Botani Zoologi dan Mikrobiologi 03:2028.

Rahardiyanti S. 2005. Kajian Pertumbuhan Setek Batang Sagitan (Sambucus javanica Reinw) di persemaian dan lapangan. Departemen Konservasi Sumberdaya Hutan dan Ekowisata Fakultas Kehutanan Bogor: IPB.

Sakai C, Subiakto A. 2007. Pedoman Pembuatan Setek Jenis-jenis (Dipterokarpa) dengan Koffco System. Bogor: Balai Penelitian dan Pengembangan Hasil Hutan Konservasi Alam.

Sriyanti PD. 2000. Pelestarian tanaman nilam (Pogostemon heyneanus Benth.) melalui kultur mikrostek. Journalof Biological Science 2:21-25.

Haji AG. 2010. Pengaruh komarasca (kompos arang aktif asap cair) dari hasil pengolahan sampah organik pada tanaman (Gynura pseudochna Lour DC). Biologi Edukasi 2:28-35.

Salisbury FB, Ross CW. 1995. Fisiologi Tumbuhan Perkembangan Tumbuhan dan Fisiologi Lingkungan . Institut Teknologi Bandung: Bandung.

Komarayati S, Gusmailina, Pari G. 2013. Arang dan cuka kayu produk hasil hutan bukan kayu untuk meningkatkan pertumbuhan tanaman dan serapan hara karbon. Jurnal Penelitian Hasil Hutan 31:49-62. 